Article

\title{
Compressive Alginate Sponge Derived from Seaweed Biomass Resources for Methylene Blue Removal from Wastewater
}

\author{
Xiaojun Shen ${ }^{1,2}$, Panli Huang ${ }^{1}$, Fengfeng Li $^{1}$, Xiluan Wang ${ }^{1, *} \mathbb{C}$, Tongqi Yuan ${ }^{1, *}$ \\ and Runcang Sun 1,3 \\ 1 Beijing Key Laboratory of Lignocellulosic Chemistry, Beijing Forestry University, Beijing 100083, China; \\ shenxiaojun@iccas.ac.cn (X.S.); huangpanli@bjfu.edu.cn (P.H.); qhxylifeng@163.com (F.L.); \\ rcsun3@bjfu.edu.cn (R.S.) \\ 2 Beijing National Laboratory for Molecular Sciences, Key Laboratory of Colloid and Interface and \\ Thermodynamics, Institute of Chemistry, Chinese Academy of Sciences, Beijing 100190, China \\ 3 Center for Lignocellulose Science and Engineering, and Liaoning Key Laboratory Pulp and Paper \\ Engineering, Dalian Polytechnic University, Dalian 116034, China \\ * Correspondence: wangxiluan@bjfu.edu.cn (X.W.); ytq581234@bjfu.edu.cn (T.Y.); \\ Tel.: +86-10-6233-6903 (X.W. \& T.Y.)
}

Received: 12 April 2019; Accepted: 20 May 2019; Published: 2 June 2019

\begin{abstract}
Low cost fabrication of water treatment polymer materials directly from biomass resources is urgently needed in recent days. Herein, a compressive alginate sponge (AS) is prepared from seaweed biomass resources through a green two-step lyophilization method. This material is much different from conventional oven-, air-, vacuum-dried alginate-based adsorbents, which show limitations of shrinkage, rigidness, tight nonporous structure and restricted ions diffusion, hindering its practical applications, and was used to efficiently remove methylene blue (MB), a main colorful contaminant in dye manufacturing, from wastewater. The batch adsorption studies are carried out to determine the impact of $\mathrm{pH}$, contact time and concentration of dye on the adsorption process. The maximum adsorption capacity can be obtained at $1279 \mathrm{mg} \mathrm{g}^{-1}$, and the shape-moldable AS can be facilely utilized as a fixed-bed absorption column, providing an efficient approach for continuous removal of MB within a short time. It is also important that such a compressive AS can be regenerated by a simple squeezing method while retaining about $70 \%$ capacity for more than ten cycles, which is convenient to be reused in practical water treatment. Compressive AS demonstrates its merits of high capability, large efficiency and easy to recycle as well as low cost resources, indicating widespread potentials for application in dye contaminant control regarding environmental protection.
\end{abstract}

Keywords: alginate sponge; two-step lyophilization; methylene blue; adsorption capacity; biomass resources

\section{Introduction}

Recently, industrial developments led to the undesirable environmental problems in the world, especially water pollution [1-3]. Many industries like the textile industry produce much wastewater, which contains a number of contaminants, including acidic or caustic dissolved solids, toxic compounds, and any different dyes, many of these dyes are carcinogenic, mutagenic, and teratogenic and also toxic to human beings, fish species, and microorganisms [1,4-8]. Among these contaminants, dyes are common contaminants in water discharged from various industries, such as plastics, textiles, printing, paper and leather industry. Due to its complex aromatic molecular structures, dyes in contaminated water are stable and resistant to biodegradation, which has become a serious environmental 
problem [9-11]. Therefore, the development of industrially applicable and efficient treatments for dye containing effluents is urgently needed [12-14]. Technologies such as coagulation/flocculation [15], biological treatment [16], oxidation or ozonation [17], membrane separation [18], electrochemical methodology [19] and adsorption [20] have been extensively applied to remove dye pollutants from wastewater. Among them, adsorption method is quite popular due to its convenience, ease of operation, low energy consumption and availability of various adsorbents [21-24]. Currently, a number of adsorbent materials, such as activated carbon [25], mesoporous silica [26], hybrid xerogel [27], nanoporous alumina [28], zeolites [29] and carbon-based nanomaterials [13], have demonstrated their capability as an effective adsorbent for dye contaminants. However, their widespread use in water treatment is sometimes restricted due to its high cost and complexity of material preparation.

Recently, the three-dimensional (3D) porous structures ensure a large surface area for efficient dye adsorption, and exhibits the desirable merits of biocompatibility, biodegradability and economic efficiency [30]. Hence, much attention has been paid to developing sponge and porous materials as absorbers and they can achieve oil-water separation via a simple, fast, and effective absorption process [31-35]. Generally, an ideal absorbent material should have high oil absorption capacity, high selectivity, low density, and excellent recyclability, and it should be environmentally friendly. A large variety of low-cost adsorbents including natural species (plant fiber [36], silk cotton [37], leaves [38], etc.), industrial/agricultural wastes or by-product (citrus waste peels [39], bagasse [40], rice husk [41], etc.) and extractive biopolymers (chitosan [42], guar gum [43], alginate [44-47], etc.) have been explored as they are inexpensive, non-toxic and environmentally friendly. In the past few years, numerous efforts have been focused on the development of more effective and cheaper adsorbents derived from natural biomass resources rather than commercial adsorbents. Alginate, isolated from natural brown seaweeds, is a linear, unbranched and anionic polysaccharide biopolymer composed of $\beta$-D-mannuronic acid (M) and $\alpha$-L-guluronic acid $(\mathrm{G})$ units in the form of homopolymeric (MMor GG-blocks) and heteropolymeric sequences (MG or GM-blocks) [48-50]. Alginate can be facilely converted into a porous sponge monolith forming the so-called "egg-box" conjunct structure [51]. In addition, the presence of negative carboxylate functional groups along polymer chains provides sufficient active sites, which guarantees its high affinity and binding ability for dye species [52,53]. Previous studies have demonstrated that conventional oven-, air-, vacuum-dried alginate-based adsorbents show limitations of shrinkage, rigidness, tight nonporous structure and restricted ions diffusion, hindering its practical applications [54].

In the paper, our aim is the fabrication of sponge-like adsorbing polymers directly from biomass resources, which is consistent with the object of low cost and renewable material design. Herein, we describe a green two-step lyophilization strategy to prepare a compressive alginate sponge (AS) derived from natural seaweed biomass resources with a large surface area, high porosity and controllable morphology. This method has advantages of low cost, simple and eco-friendly approach that does not include toxic or expensive resources, complicated or multistep chemical reactions. In this work, the as-prepared sponge was used to efficiently remove methylene blue (MB), a main colorful contaminant in dye manufacturing, from aqueous solution through the batch and continuous fixed-bed column adsorption. Their kinetics, thermodynamic analysis and adsorption mechanism are investigated. More importantly, the regeneration of the compressive sponge just by squeezing demonstrates its large potential to be used in practical applications for water treatment.

\section{Materials and Methods}

\subsection{Materials}

Waste brown seaweeds were collected from Shandong province, China. It was exhaustively washed with tap water, air-dried, and cut into pieces before use. Sodium carbonate ( $\geq 99.8 \%)$, calcium chloride $(\geq 96.0 \%)$, hydrochloric acid (36.0 38.0\%), sodium hydroxide ( $\geq 96.0 \%)$, methylene blue $(\geq 90 \%)$ were purchased from Sinoparm Chemical Reagent Beijing Co., Ltd (Beijing, China). 


\subsection{Extraction of Seaweed}

Sodium alginate was extracted from seaweed resources according to our previous work in our lab [43]. Firstly, the pigments of seaweed samples ( $5 \mathrm{~g}$ ) on the surface were fixed by soaking in $1 \mathrm{wt} \%$ formaldehyde solution $(300 \mathrm{~mL})$. Then, the seaweeds were treated with $4 \mathrm{wt} \% \mathrm{Na}_{2} \mathrm{CO}_{3}(300 \mathrm{~mL})$ at $46{ }^{\circ} \mathrm{C}$ for $3 \mathrm{~h}$. After that, the mixture was filtered, neutralized and precipitated by dropping the $10 \mathrm{wt} \% \mathrm{CaCl}_{2}$ to obtain the calcium alginate. The crude calcium alginate was washed thoroughly with distilled water and then acidified with $5 \mathrm{wt} \% \mathrm{HCl}$ for $1 \mathrm{~h}$. After that, gel materials of alginic acid were gained by filtering and washed several times with distilled water. The alginic acid was then dispersed in distilled water and converted into sodium alginate by neutralization $(\mathrm{pH} 6-7)$ with $1 \mathrm{wt} \% \mathrm{NaOH}$. Finally, the sodium alginate was precipitated and purified by ethanol, and collected for further use after freeze-drying. Its weight-average molecular weight $(\mathrm{Mw})$ and $\mathrm{M} / \mathrm{G}(\mathrm{M}$ is $\beta$-D-mannuronic acid and $\mathrm{G}$ is $\alpha$-L-guluronic acid) value were $1.51 \times 10^{6} \mathrm{~g} \mathrm{~mol}^{-1}$ and 0.86 , respectively.

\subsection{Preparation of $A S$}

The AS was prepared by a green two-step lyophilization method from seaweed biomass resources, which was presented in Scheme 1. $0.2 \mathrm{~g}$ sodium alginate powder extracted from seaweed biomass resources was dissolved in $9.8 \mathrm{~g}$ distilled water $(2 \mathrm{wt} \%)$ under vigorous stirring until homogeneous dispersion was formed. Then, the alginate solution was carefully cast into Petri dish plates and freeze-dried at $-50{ }^{\circ} \mathrm{C}$ for $48 \mathrm{~h}$. After that, the lyophilized sodium alginate sample was rinsed with $5 \mathrm{wt} \% \mathrm{CaCl}_{2}$ aqueous solution under quiescent conditions. The ionic crosslinking process was maintained for $12 \mathrm{~h}$ allowing the $\mathrm{Ca}^{2+}$ ions to be fully crosslinked with sodium alginate. Hereafter, the crosslinked alginate sample was soaked with distilled water and washed for several times to remove the excessive salts. After that, the ionic crosslinked sample was freeze-dried at $-50{ }^{\circ} \mathrm{C}$ for $48 \mathrm{~h}$. The as-obtained AS could be cut and shaped into different geometrical shapes easily by scissors and cutters. For clearly understanding, the involved chemical equations of different steps in Scheme 1 were supported by Scheme S1.

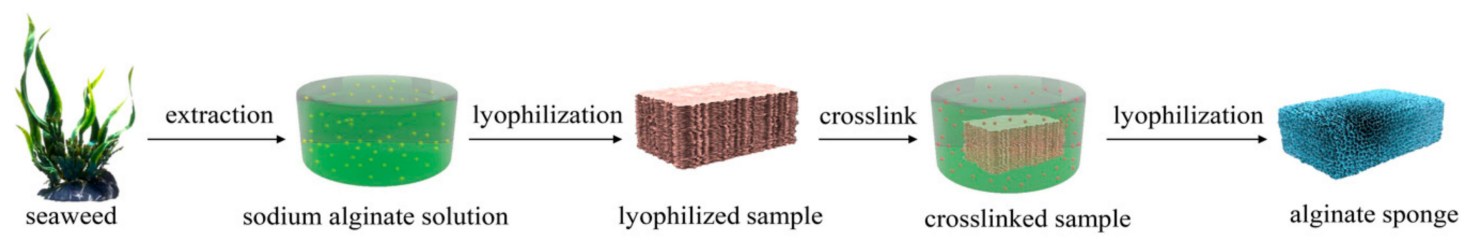

Scheme 1. The scheme of the two-step lyophilization method for the preparation of compressive alginate sponge (AS) from seaweed biomass resources.

\subsection{Characterizations}

The morphology of the AS was examined by the field-emission scanning electron microscope (SEM) (HitachiS-5500, Tokyo, Japan) operating at $10 \mathrm{kV}$ acceleration voltage. All samples were coated with gold prior to acquiring the images. The pore size distributions were calculated by the Mercury Intrusion Porosimetry (Demo AutoPore IV 9500, Micromeritics, Atlanta, GA, USA). The Fourier transform infrared spectroscopy (FT-IR) spectra of the AS was collected by a Thermo Scientific Nicolet iN10 FT-IR Microscope (Thermo Nicolet Corporation, Waltham, MA, USA) equipped with an MCT detector cooled by liquid nitrogen in the reflection mode. The spectra were recorded in the range from 4000 to $670 \mathrm{~cm}^{-1}$ with 64 scans at a $4 \mathrm{~cm}^{-1}$ resolution. The crystalline structure measurement was performed on an XRD-7000 X-ray diffractometer (Shimadzu, Kyoto, Japan) with a $\mathrm{Cu} \mathrm{K} \alpha$ radiation source $(\lambda=0.154 \mathrm{~nm})$ at $40 \mathrm{kV}$ and $30 \mathrm{~mA}$. The X-ray photoelectron spectra (XPS) were determined on the photoelectron spectrometer (ESCALAB 250Xi, Thermo Fisher, Waltham, MA, USA) using an Al K $\alpha$ $(1486.6 \mathrm{eV})$ radiation. Mechanical properties were carried out on a UTM6503 universal tensile Machine (Shenzhen Suns Technology stock CO. LTD. Shenzhen, China) equipped with a $100 \mathrm{~N}$ load cell at the 
rate of $10 \mathrm{~mm} \mathrm{~min}^{-1}$. The thermal behaviour was studied by thermogravimetric analyses (TGA) using a DTG-60 simultaneous thermal analyzer (Shimadzu, Tokyo, Japan) under nitrogen atmosphere. 3-6 mg samples were loaded in an alumina crucible and heated from $40{ }^{\circ} \mathrm{C}$ to $900{ }^{\circ} \mathrm{C}$ at the rate of $10^{\circ} \mathrm{C} \mathrm{min}-1$.

\subsection{Adsorption Measurement}

The dye adsorption capability for AS was investigated at room temperature with methylene blue (MB). The MB solution was prepared by dissolving the MB powder in deionized water. Then, it was diluted with deionized water into a desired concentration varied between 50-1800 $\mathrm{mg} \mathrm{L}^{-1}$. Typical batch adsorption tests were accomplished by suspending $20 \mathrm{mg}$ AS in $50 \mathrm{~mL} \mathrm{MB}$ aqueous solution with different concentrations at an initial natural $\mathrm{pH}$ value in a flask. Afterwards, the flask was continuously shaken in a rotary shaker with $100 \mathrm{rpm}$ for a period time to reach the adsorption equilibrium. In the study of the $\mathrm{pH}$ effect, the required $\mathrm{pH}$ value of the solution was adjusted with $0.1 \mathrm{~mol} \mathrm{~L}^{-1} \mathrm{HCl}_{\text {or }}$ $\mathrm{NaOH}$ aqueous solutions. After the adsorption equilibrium, the residual concentrations of the $\mathrm{MB}$ supernatants were evaluated by an UV-vis spectrometer at the absorbance of $664 \mathrm{~nm}$. The amount of MB adsorbed by AS was calculated as following equation:

$$
Q_{\mathrm{e}}=\frac{\left(C_{0}-C_{\mathrm{e}}\right) V}{m}
$$

where $Q_{e}\left(\mathrm{mg} \mathrm{g}^{-1}\right)$ represents the adsorption capacity at equilibrium, $C_{0}\left(\mathrm{mg} \mathrm{L}^{-1}\right)$ and $C_{\mathrm{e}}\left(\mathrm{mg} \mathrm{L}^{-1}\right)$ are the $\mathrm{MB}$ concentrations at the initial and equilibrium, respectively. $V$ is the volume of the solution $(\mathrm{mL})$, and $m$ is the mass of dry adsorbent (mg).

The continuous fixed-bed column adsorption experiments were conducted in a U-tube glass column with an inner diameter of $0.8 \mathrm{~cm}$ and volume capacity of $15 \mathrm{~mL}$. The AS was cut with the desired column (diameter: $0.8 \mathrm{~cm}$, height: $0.45 \mathrm{~cm}$, weight: $7.8 \mathrm{mg}$ ) and then packed into the glass column tightly. Two layers of adsorbent cotton and bugles (diameter 400-800 $\mu \mathrm{m}$ ) were embedded on the top and bottom of the packed column. $50 \mathrm{~mL} \mathrm{MB}$ solution with an initial concentration of $1000 \mathrm{mg} \mathrm{L}^{-1}$ was pumped through the column in a down-flow mode using a peristaltic pump with the rate of $10 \mathrm{~mL} \mathrm{~min}^{-1}$ at room temperature.

\section{Results and Discussions}

\subsection{Material Properties}

The as-obtained sponge was elastic enough to be easily handled and cut into desired shapes, such as rods, cylinders, papers or cubes to satisfy various absorption requirements (Figure 1a). Moreover, the AS has an ideal density $\left(34.6 \mathrm{mg} \mathrm{cm}^{-3}\right)$ compared with conventional compacted alginate-based materials [54], which could effortlessly stand on a grass leaf (Figure 1b). The strength and lightweight of AS were closely related to its three-dimensional (3D) porous framework with abundant pores as shown in Figure 1c,d. As a result, the interior sponge possessed a wide range of pore sizes from nanometers to hundreds of micrometers (mostly less than $100 \mu \mathrm{m}$ ) calculated by the mercury intrusion porosimetry method (Figure S1). The FT-IR analysis and XRD pattern revealed that the carboxyl groups penetrated in the AS network and the AS has none of the distinct crystalline formation (Figure 1e,f). Through the photoelectron lines of the wide-scan XPS spectrum (Figure S2), the presence of carbon (57.72\% area), oxygen $(39.03 \%$ area) and calcium (3.25\% area) atoms in the AS were confirmed. Further investigation of atomic binding states on the surface of the AS was conducted by XPS analysis (Figure 1g,h). 

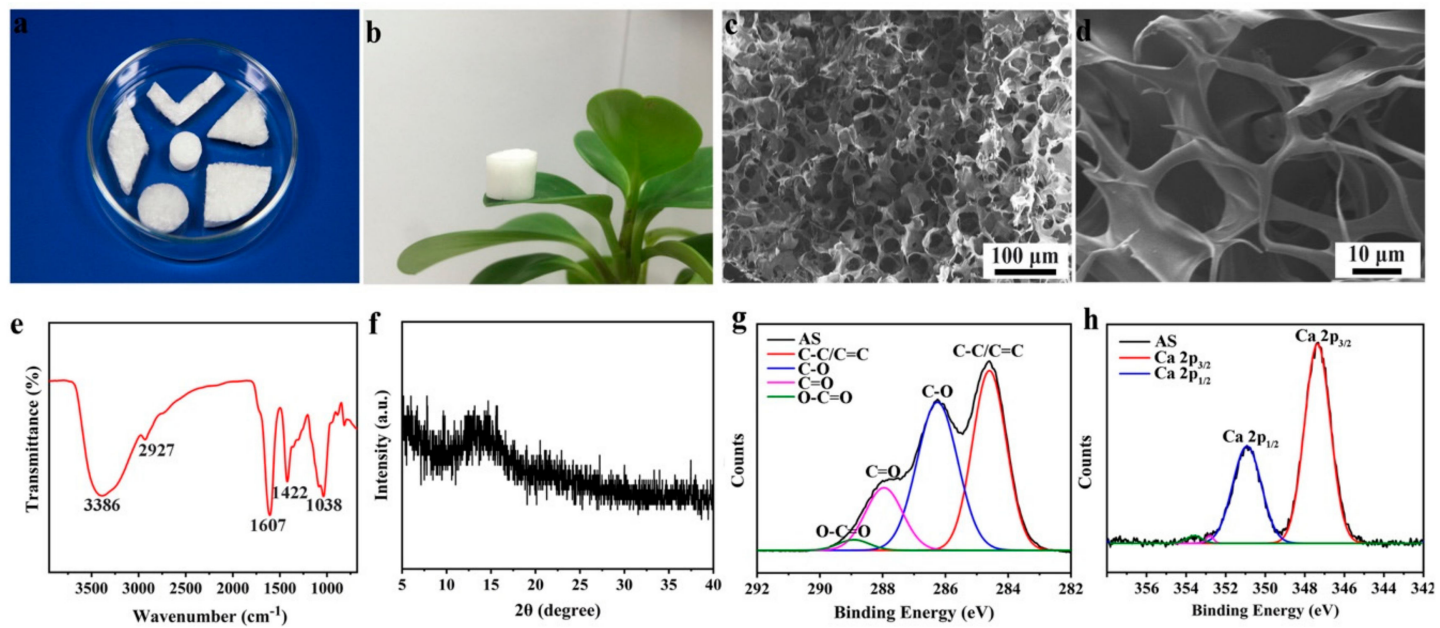

Figure 1. (a) Photographs of AS with desired shapes which is easy to be handled and cut by scissors; (b) a photograph of a column of AS free-standing on a grass leaf to support its weight; (c,d) SEM images of AS samples with different magnifications; (e) the FT-IR spectra and (f) the XRD pattern of AS; $(\mathbf{g}, \mathbf{h})$ high-resolution XPS of C 1s peaks and Ca 2 p peaks for AS.

\subsection{Absorption Properties}

The 3D multiporosity and large active surfaces of AS make it an ideal candidate for the removal of methylene blue $(\mathrm{MB})$ dye from wastewater. It should be noted that the initial $\mathrm{pH}$ value plays a significant role in the adsorption performances. It determines the adsorption reactions between $\mathrm{MB}$ and the adsorbent surface, attributing to the ionization in the solution and charge distribution on the adsorbent surface. In order to optimize the $\mathrm{pH}$ value to obtain the maximum adsorption capacity, batch adsorption experiments were conducted at $\mathrm{pH}$ values ranging from 2.0 to 10.0 with an initial $\mathrm{MB}$ concentration of $1000 \mathrm{mg} \mathrm{L}^{-1}$ for a contact time of $12 \mathrm{~h}$. As shown in Figure 2a, the adsorption capacity was strongly related to the initial $\mathrm{pH}$ value. The lowest valve of $Q_{\mathrm{e}}\left(188 \mathrm{mg} \mathrm{g}^{-1}\right)$ was found at the $\mathrm{pH}$ value of 2.0. It can be speculated that surfaces of AS were highly protonated due to the high concentration of $\mathrm{H}^{+}$. Thus, the $-\mathrm{COO}^{-}$active sites for adsorption of $\mathrm{MB}$ were occupied and those surface negative charges that were reduced, weaken the electrostatic attraction forcers between surfaces of AS and MB. Resultantly, the adsorption capacity is decreased with the decrease of $\mathrm{pH}$ from 4 to 2 . However, when the $\mathrm{pH}$ value was higher than 4.0 (above the $\mathrm{pKa}$ value of $\mathrm{MB}$ ), the surface charges of AS became more negative which was confirmed by Zeta potential data, promoting the electrostatic interaction between surface active sites and adsorbate, improving the adsorption capacity for $\mathrm{MB}$. Additionally, the presence of excess of $\mathrm{H}^{+}$ions at low $\mathrm{pH}$ will compete with the $\mathrm{MB}$ cations for adsorption sites, resulting in a decrease of adsorption capacity, while more negatively charged surfaces of adsorbents become available with increased $\mathrm{pH}$ value $[55,56]$. This efficient adsorption behavior of the $\mathrm{AS}$ at $\mathrm{pH}=4-10$ demonstrates that it is potentially applicable in a relatively wide $\mathrm{pH}$ range. Nonetheless, considering the instability of calcium alginate in the strong alkaline condition, all the following experiments were conducted at $\mathrm{pH}=4$.

To evaluate the adsorption capacity of AS for $\mathrm{MB}$, adsorption isotherms with different initial $\mathrm{MB}$ concentrations (5-1800 mg L ${ }^{-1}$ ) were measured at room temperature of $25^{\circ} \mathrm{C}$ with a contact time of $12 \mathrm{~h}$. As shown in Figure $2 \mathrm{~b}$, it could be distinctly observed that the value of adsorption capacity increased with the increase of initial MB concentrations, until trended toward the equilibrium state. This can explain that the higher initial concentration generated a stronger driving force resulting from the concentration gradient, in favor of a mass transfer for MB from aqueous solution to adsorbent. With the initial concentration up to $1000 \mathrm{mg} \mathrm{L}^{-1}$, the active adsorption sites of the adsorbent were almost occupied by MB molecules, thus the adsorption capacity attained at the maximum value and kept constant even at higher initial concentration of MB [57]. The equilibrium adsorption capacity could finally reach at $1279 \mathrm{mg} \mathrm{g}^{-1}$ with the initial MB concentration of $1800 \mathrm{mg} \mathrm{L}^{-1}$. In addition, we also 
calculated the removal ratio of the sponge at different initial concentrations of MB. A higher removal ratio about $90 \%$ was obtained at the relatively low initial concentration. Even at low concentrations of 5 and $10 \mathrm{mg} \mathrm{L}^{-1}$, the AS also has high sensitivity for efficient MB removal, which is important for adsorbents used in the water treatment. A clear comparison of the removal effect could be presented by the images before and after batch adsorption (Figure S3). In additional, the AS before and after adsorbing methylene blue was characterized by the FT-IR spectra. As shown in Figure S4, the infrared characteristic peaks ( 1607 and $1422 \mathrm{~cm}^{-1}$ ) of the $\mathrm{C}=\mathrm{O}$ group shifted to low infrared absorption peak, which suggested that the internal porous structure of AS was favorable to the electrostatic interaction between the polymer carboxylic functional groups and cationic groups of the MB.
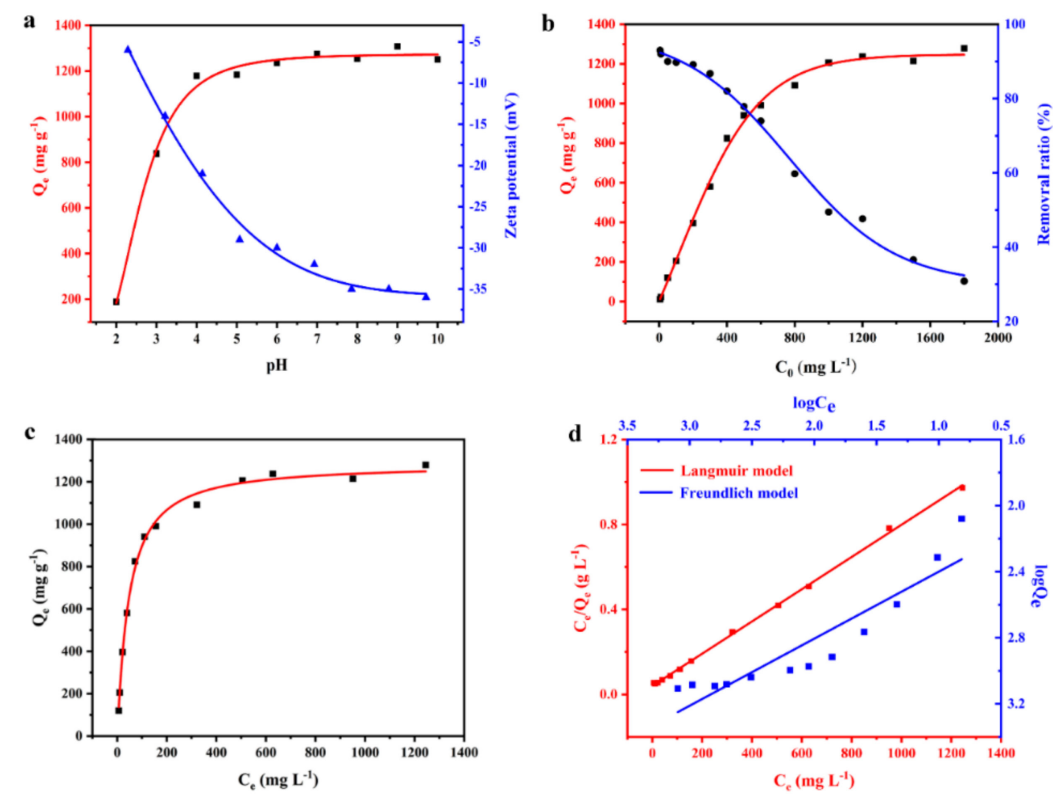

Figure 2. (a) The effect of the initial $\mathrm{pH}$ value on adsorption capacities of AS for methylene blue (MB) removal and the $\mathrm{pH}$ dependence of Zeta potential variation of $\mathrm{MB}$ adsorbed onto $\mathrm{AS}$; (b) the removal ratio of $\mathrm{AS}$ for $\mathrm{MB}$ at different initial MB concentrations; (c) the adsorption isotherm of $\mathrm{AS}$ for $\mathrm{MB}$ removal; (d) the fitting adsorption data for the Langmuir and the Freundlich isotherm models.

The adsorption isotherm is essential for the adsorption to further explore its adsorption mechanism. In this study, the Langmuir and Freundlich isotherm models were used to fit the adsorption data, respectively, based on the adsorption isotherm of MB (Figure 2c). The Langmuir isotherm model assumes its monolayer adsorption over a homogeneous adsorbent surface with adsorption sites that are identical and energetically equivalent. Therefore, it can achieve at a saturate state without further adsorption activities. On the other hand, the Freundlich isotherm model is an empirical equation, which is employed to describe a multilayer adsorption onto heterogeneous surfaces with undefined sites. The two isotherm models can be described by two equations as follows:

$$
\begin{gathered}
\frac{C_{e}}{Q_{e}}=\frac{C_{e}}{Q_{m}}+\frac{1}{K_{L} Q_{m}} \\
\log Q_{\mathrm{e}}=\log K_{\mathrm{F}}+\frac{1}{n} \log C_{\mathrm{e}}
\end{gathered}
$$

where $C_{\mathrm{e}}$ is the final equilibrium concentration $\left(\mathrm{mg} \mathrm{L}^{-1}\right), Q_{\mathrm{e}}$ is the adsorption capacity at equilibrium $\left(\mathrm{mg} \mathrm{g}^{-1}\right), Q_{\mathrm{m}}$ is the maximum adsorption capacity $\left(\mathrm{mg} \mathrm{g}^{-1}\right), K_{\mathrm{L}}$ is the Langmuir constant $\left(\mathrm{L} \mathrm{mg}^{-1}\right)$, $K_{\mathrm{F}}$ is a constant related to the adsorption capacity $\left(\mathrm{mg} \mathrm{g}^{-1}\right)\left(\mathrm{L} \mathrm{mg}^{-1}\right)^{1 / \mathrm{n}}$ and $n$ is an empirical parameter related to the adsorption intensity. 
The linearized Langmuir and Freundlich adsorption isotherm plots were drawn as Figure 2d and their parameters were calculated from the adsorption isotherms listed in Table 1. The higher correlation coefficient $\left(R^{2}=0.9991\right)$ of the Langmuir isotherm model indicated that it was better than the Freundlich isotherm model $\left(R^{2}=0.8515\right)$ in simulating our experiment data. The fitting result presented that the adsorption behavior occurred on homogeneous surfaces of AS through a monolayer manner. Moreover, according to the Langmuir fitting result, the maximum adsorption capacity for MB of AS was $1310 \mathrm{mg} \mathrm{g}^{-1}$ in high concordance with the experimental equilibrium value $\left(1279 \mathrm{mg} \mathrm{g}^{-1}\right)$, which is comparable with alginate based or other reported adsorbents for the MB adsorption listed in Table S1 and Table S2. Importantly, the synthesis of the AS adsorbent is quite green, economic and might be applied for large-scale production.

Table 1. Langmuir and Freundlich model fitting parameters for MB adsorption on AS.

\begin{tabular}{ccc}
\hline Isotherm Model & Parameter & Value \\
\hline \multirow{2}{*}{ Langmuir model } & $Q_{m}\left(\mathrm{mg} \mathrm{g}^{-1}\right)$ & 1317 \\
& $K_{L} \times 10^{-2}\left(\mathrm{~L} \mathrm{mg}^{-1}\right)$ & 1.90 \\
& $R^{2}$ & 0.9991 \\
\hline \multirow{2}{*}{ Freundlich model } & $K_{F}\left(\mathrm{mg} \mathrm{g}^{-1}\right)\left(\mathrm{L} \mathrm{mg}^{-1}\right)^{1 / \mathrm{n}}$ & 98.5845 \\
& $n$ & 2.4643 \\
& $R^{2}$ & 0.8515 \\
\hline
\end{tabular}

The adsorption kinetics was examined by measuring the adsorption capacity at initial MB concentrations of 500 and $1000 \mathrm{mg} \mathrm{L}^{-1}$, respectively. The samples were collected at different time intervals up to $12 \mathrm{~h}$. Figure 3 a shows the effect of contact time on the adsorption capacity of AS for MB with different initial concentrations at an ambient temperature. It demonstrated that the adsorption capacity increased rapidly at the initial adsorption stage, then increased with the contact time at a relatively slow rate, and reached up to the equilibrium within $390 \mathrm{~min}$. The adsorption capacity increased with higher initial concentrations, since the surface coverage was relatively low in the early stage, thus dye molecules could occupy the vacant adsorption sites rapidly. Once the adsorption process approached at the equilibrium, there would be less vacant active sites. Furthermore, the adsorbed MB molecules on the surface of AS could repel free MB molecules via the electrostatic repulsion.

To investigate the kinetic mechanism, the pseudo-second-order equation was used to describe the adsorption process. The time-dependent adsorption process was analysed using the pseudo-first-order and pseudo-second-order kinetic models (Figure 3b) according to the following equations:

$$
\begin{gathered}
\log \left(Q_{1 \mathrm{e}}-Q_{\mathrm{t}}\right)=\log Q_{1 \mathrm{e}}-\frac{k_{1} t}{2.303} \\
\frac{\mathrm{t}}{Q_{\mathrm{t}}}=\frac{1}{k_{2} Q_{2}{ }^{2}}+\frac{t}{Q_{2 \mathrm{e}}}
\end{gathered}
$$

where $k_{1}\left(\mathrm{~min}^{-1}\right)$ is the pseudo-first-order rate constant; $k_{2}\left[\mathrm{~g}(\mathrm{mg} \cdot \mathrm{min})^{-1}\right]$ is the pseudo-second-order kinetic rate constant; $Q_{\mathrm{e}}$ and $Q_{\mathrm{t}}$ are the amounts $\left(\mathrm{mg} \mathrm{g}^{-1}\right)$ of adsorption at the equilibrium and at contact time referred as $t(\mathrm{~min})$. The pseudo-first-order assumes that the adsorption rate linear declines with the increase of the removal efficiency. The pseudo-second-order holds the opinion that the rate-controlling step of adsorption is the interaction between the adsorbent and adsorbate, such as ion sharing and transferring [19]. 

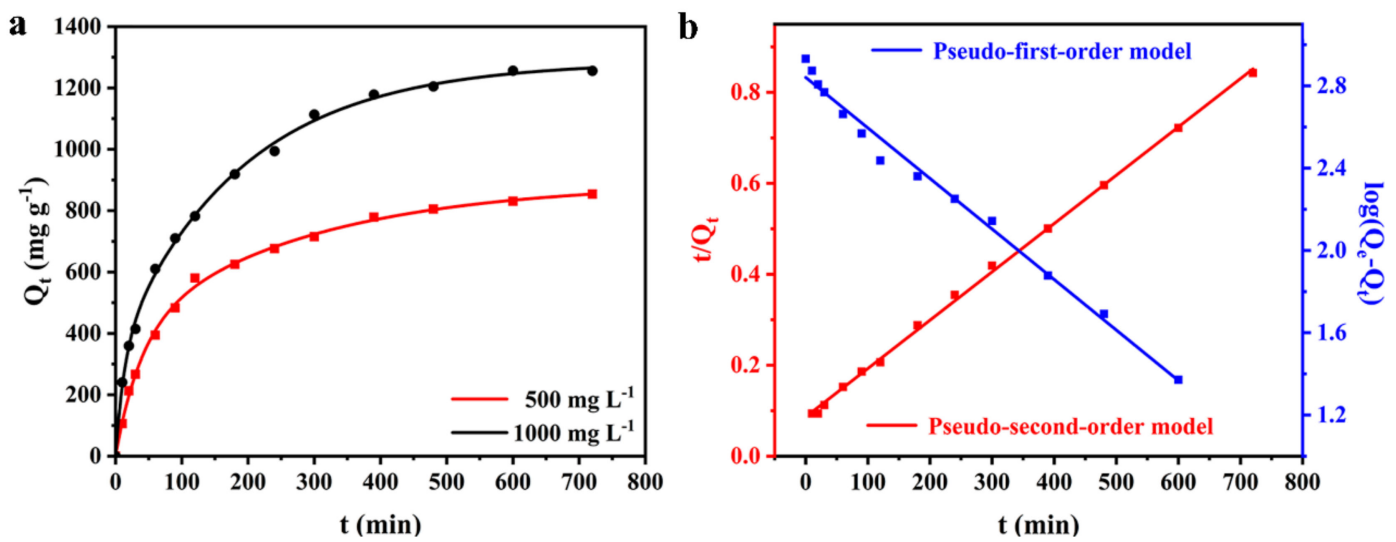

Figure 3. (a) The adsorption kinetic of $\mathrm{AS}$ for $\mathrm{MB}$ removal at initial $\mathrm{MB}$ concentrations of 500 and $1000 \mathrm{mg} \mathrm{L}^{-1}$; (b) the fitting adsorption data for the pseudo-first-order and the pseudo-second-order kinetic models, $\mathrm{C}_{0}=500 \mathrm{mg} \mathrm{L}^{-1}$.

The kinetic model parameters were obtained by the regression analysis of the experimental data (Table 2). It can be observed that the $R^{2}$ values for the pseudo-first order kinetic model was lower than that for the pseudo-second-order kinetic model. The pseudo-second-order kinetic model $\left(R^{2}=0.9988\right)$ provided a better correlation in contrast to the pseudo-first-order kinetic model $\left(R^{2}=0.9890\right)$ for MB adsorption. Additionally, the values of $Q_{1 \mathrm{e}}\left(694 \mathrm{mg} \mathrm{g}^{-1}\right)$ failed to predicate the values of $Q_{\text {exp }}$, while the values of $Q_{2 \mathrm{e}}\left(943 \mathrm{mg} \mathrm{g}^{-1}\right)$ is pretty close to $Q_{\exp }\left(845 \mathrm{mg} \mathrm{g}^{-1}\right)$, confirming that the kinetics of MB adsorption was identical when described by the pseudo-second-order kinetic model rather than the pseudo-first-order model. It means that the overall adsorption rate seems to be controlled by the chemical interaction through covalent forces during the process of exchanging electrons between adsorbent and adsorbate.

Table 2. Adsorption kinetics fitting results for $\mathrm{MB}$ on alginate sponge by pseudo-first-order and pseudo-second-order models.

\begin{tabular}{ccc}
\hline Isotherm Model & Parameter & Value \\
\hline & $Q_{\mathrm{e}}\left(\mathrm{mg} \mathrm{g}^{-1}\right)$ & 694 \\
Pseudo-First-Order Model & $k_{1} \times 10^{-2}\left(\mathrm{~min}^{-1}\right)$ & 0.567 \\
& $R^{2}$ & 0.9890 \\
\hline \multirow{2}{*}{ Pseudo-Second-Order Model } & $k_{2} \times 10^{-4}\left[\mathrm{mg} \mathrm{g}^{-1}\right)$ & 943 \\
& $\left.\left.R^{2} \cdot \mathrm{min}\right)^{-1}\right]$ & 0.130 \\
& & 0.9988 \\
\hline
\end{tabular}

Based on previous reported literature, the porous structure of AS favors the electrostatic interaction between the polymer carboxylic functional groups and cationic groups of the MB. A possible adsorption mechanism for MB adsorption was shown in Scheme 2. According to the "egg-box" model of gelation mechanism, the carboxyl functional groups of the $\alpha$-L-guluronic acid in sodium alginate could form ionic bonds with divalent $\mathrm{Ca}^{2+}$ ions, leading to the transformation of the alginate solution into a stable sponge and forming abundant holes, which could trap MB molecules by the carboxyl functional groups in the network of AS. In addition, the hydroxyl groups of AS could also stabilize the MB-alginate complex. 


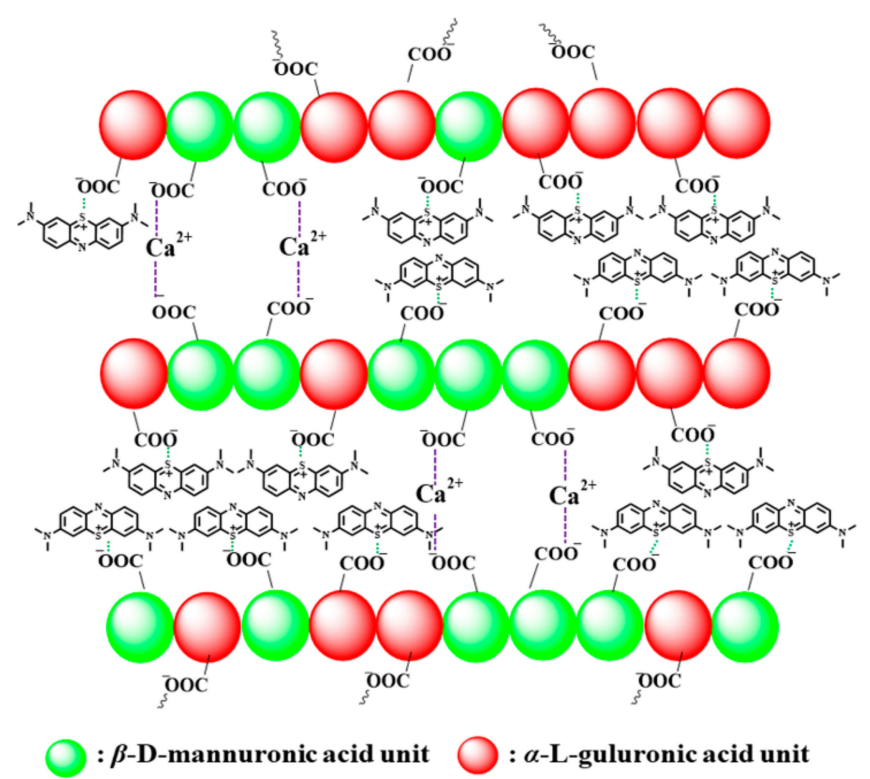

Scheme 2. The possible adsorption mechanism of AS for MB removal.

\subsection{Compressive Properties and Recyclability}

The performance of adsorbents in the continuous dyes adsorption process is an important factor in assessing the feasibility of adsorbents in real-time practical applications. Fortunately, the free-standing and elastic AS can be easily handled, superior to the other suspended adsorbents. The compressive properties of AS were examined by mechanical tests which were repeated within compress-release cycles. The AS sample exhibited excellent elastic resilience under compression, it could recover to its original morphology after removal of the external load (Figure 4a). The cyclic compression stress-strain $(\sigma-\varepsilon)$ curves at a maximum strain of $30 \%, 50 \%$, and $70 \%$ were shown in Figure $4 \mathrm{~b}$. In the first circle, the loading curve exhibited three distinct stages: (i) A linear-elastic regime during which the stress increases linearly at $\varepsilon<20 \%$, the sponge started to bend and the structure of the interior pore began to change; (ii) a plateau region at $20 \%<\varepsilon<60 \%$, the sponge was compressed to a certain extent and the increase of stress was slow; (iii) a steep slope region at $\varepsilon>60 \%$ with rapidly rising stress because of the densification of the sponge, where the stress increases linearly again. Even under a maximum strain of $70 \%$, AS can still recover its original elasticity after removal of the external load. Moreover, the maximum value of compression stress increased from 17.7 to $96.7 \mathrm{KPa}$ with compression strain increased from $30 \%$ to $70 \%$. Cyclic compression tests were also conducted as shown in Figure 4c. With the increase of the compression cycles, the hysteresis loop for the multicycle curve shrinks compared to the first circle, while after the 5 th cycle almost coincided, indicating that the plastic deformation increased but gradually become stabilized. However, the maximum stress remains unchanged, suggesting that AS can retain its compressive strength for 10 cycles with the maximum strain of $50 \%$. These phenomena can be explained by the mechanical elasticity of the pore walls constructed during the two-step lyophilization process.

Thus, we fabricated a mechanically strong and free-standing AS sample (height $1.2 \mathrm{~cm}$, volume capacity $15 \mathrm{~mL}$, internal diameter $0.8 \mathrm{~cm}$ ) into a flexible column device for fast removing $\mathrm{MB}$ from water (Figure 5a). Different from the traditional shaking adsorption in the vessel, the fixed-bed column adsorption contains dynamic behaviors allowing continuous operation. The dynamic adsorption process under constant flow provided a more efficient pathway to utilize the internal multipores in the network of AS, thus improving the adsorption efficiency in quite a short time. The continuous adsorption experiments were undertaken with different contact times treating $50 \mathrm{~mL}$ MB aqueous solution. The initial concentration of $\mathrm{MB}$ was set as $1000 \mathrm{mg} \mathrm{L}^{-1}$. The adsorption capacities along with the different contact time were presented in Figure 5b. It can be concluded that the adsorption 
capacity increased with the increasing of the contact time, and reached up to a maximum capacity of $1100 \mathrm{mg} \mathrm{g}^{-1}$ within $50 \mathrm{~min}$. Further prolonging the contact time could not enhance the adsorption capacity. This is mainly due to the fact that the interaction surface of AS can be utilized sufficiently in the first $50 \mathrm{~min}$, and the further increase of the contact time cannot improve the efficient interaction surface area. The fixed-bed column adsorption demonstrates a large potential for practical application owing to their higher efficiency as compared with traditional shaking adsorption conditions $\left(1279 \mathrm{mg} \mathrm{g}^{-1}\right.$ in $720 \mathrm{~min}$ ). The column-packed adsorbent could treat quantities of MB contained waste one time, which was considered to be an economic waste treatment.

a
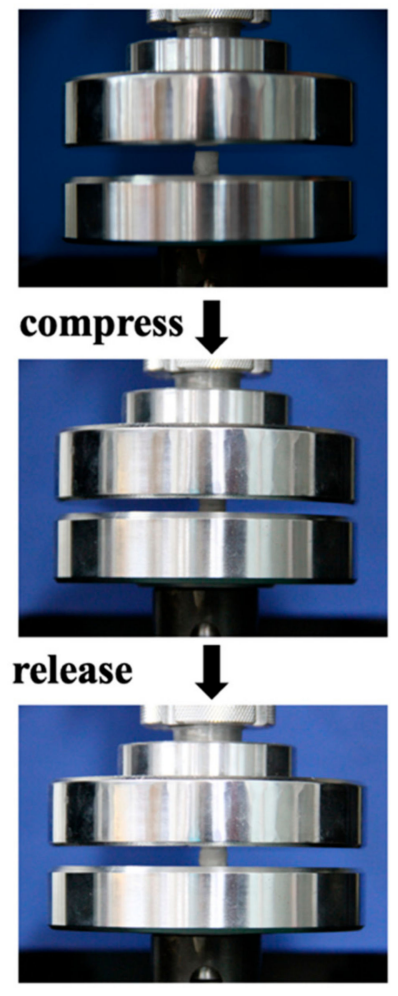

b

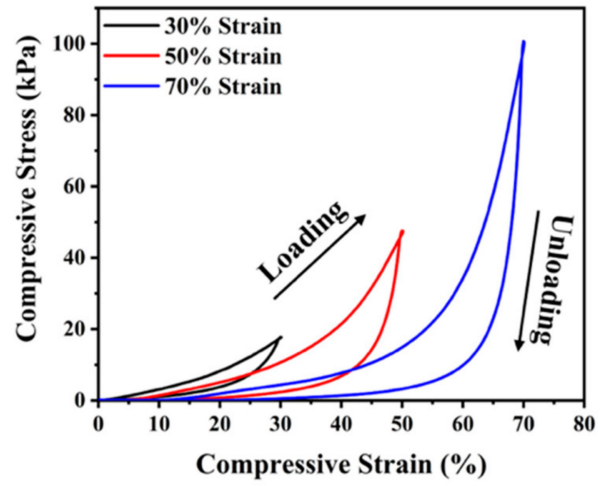

c

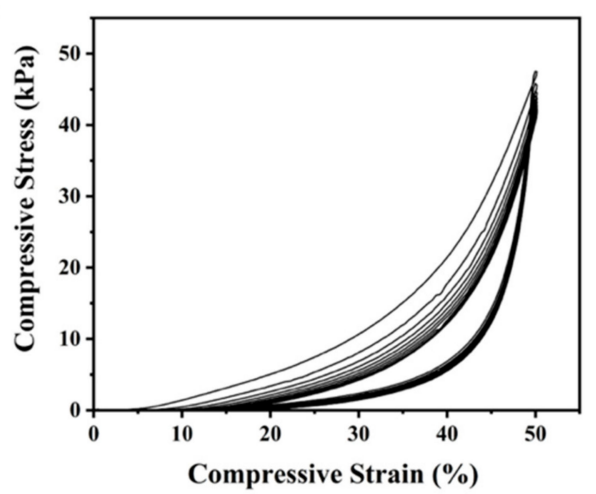

Figure 4. Mechanical compressive properties of AS. (a) A set of real-time images of a compressed sample showing the recovering process; (b) the cyclic compression stress-strain $(\sigma-\varepsilon)$ curves at maximum strain of $30 \%, 50 \%$, and $70 \%$; (c) the cyclic compression stress-strain $(\sigma-\varepsilon)$ curves for first 10 cycles at maximum strain of $50 \%$.

The recyclability is also important in pollution control applications. A simple squeezing method was applied facilely to recycle the adsorbed AS and harvest the pollutants due to its compressive properties. The recyclability test was investigated through fixed-bed column adsorption. As shown in Figure $5 c$, the adsorption capacity for MB was maintained for about $70 \%$ after 10 cycles with $861 \mathrm{mg} \mathrm{g}^{-1}$, exhibiting good recyclability upon the easy squeezing method. The main reason for the residual MB during the recycled use may be attributed to the stability of partial trapped MB molecules complexed within the network of AS chains. For further thoroughly removal of MB during the cyclic tests, chemical cleaning or heat treatment might be efficient.

Thermal stability is a key criterion to characterize the temperature limit for the environment of the absorbent during the procedure of adsorption. As shown in Figure S5, the first weight loss (about $10 \%$ ) of AS in the temperature range from 40 to $190{ }^{\circ} \mathrm{C}$ was corresponded to the evaporation of free water and water-linked hydrogen bonds [52,53]. The second mass loss of almost $40 \%$ at $190-400{ }^{\circ} \mathrm{C}$ was mainly due to the thermal destroy of glycosidic bonds for alginate polar interactions with the carboxylate groups. The final step of mass loss $\left(400-900^{\circ} \mathrm{C}\right)$ might be attributed to the carbonate 
formation under high temperature [54]. The final thermal degradation of alginate could be the result of forming $\mathrm{CaCO}_{3}$.

$\mathbf{a}$
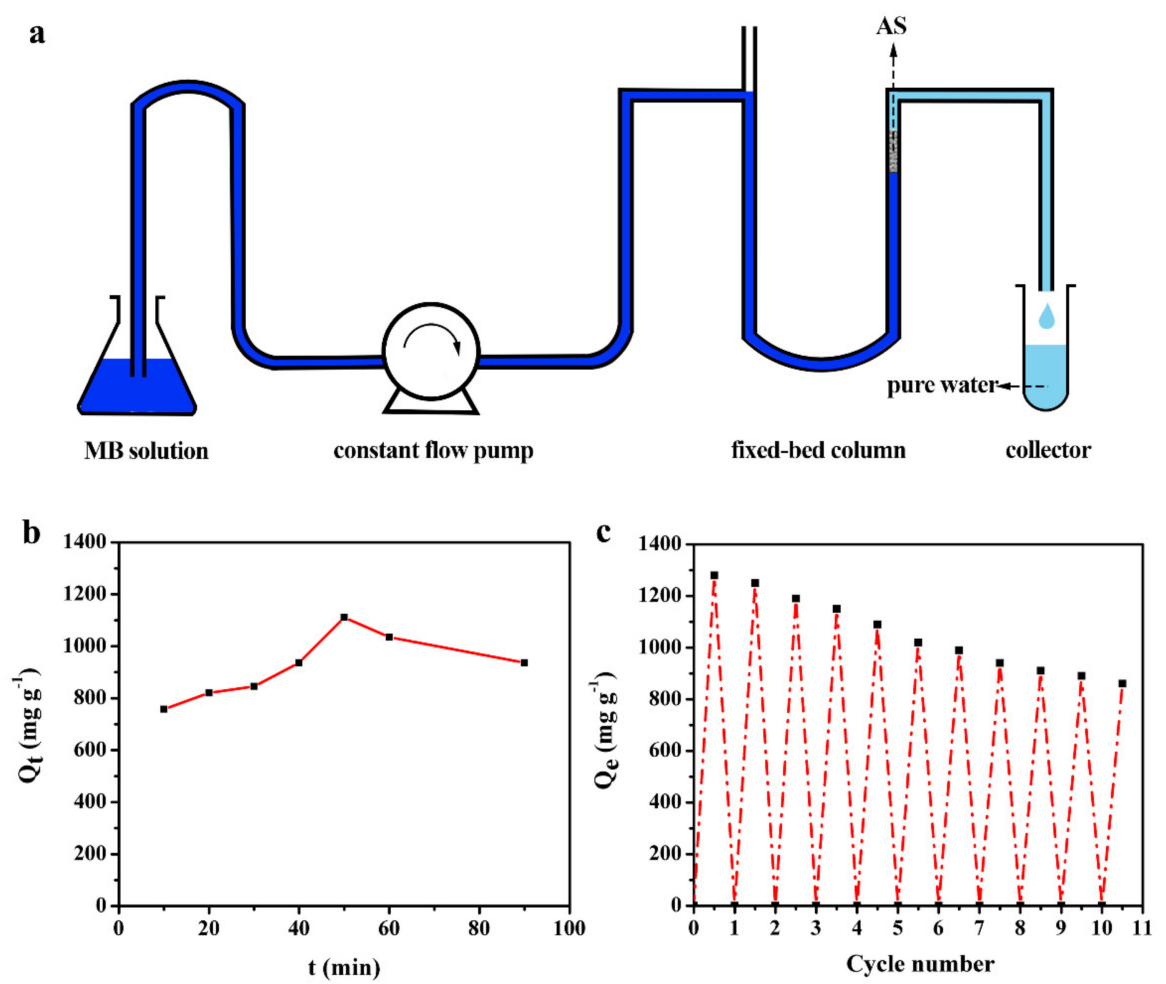

Figure 5. (a) The scheme of the adsorption process and equipment in the fixed-bed absorption column; (b) the adsorption capacities of AS with different contact time for MB removal; (c) the cyclic absorption capacities of AS for MB removal within 10 cycles through squeezing method.

\section{Conclusions}

A compressive AS was prepared from seaweed biomass resources via a green two-step lyophilization method, which was used to remove MB from wastewater for pollutant control. Due to the 3D multiporous structure, large specific surface area and sufficient active sites, the as-prepared AS exhibited high adsorption capacity $\left(1279 \mathrm{mg} \mathrm{g}^{-1}\right)$ for $\mathrm{MB}$ removal, which is much different from the conventional oven-, air-, vacuum-dried alginate-based adsorbents, which show limitations of shrinkage, rigidness, tight nonporous structure and restricted ions diffusion, hindering its practical applications. Their kinetics, thermodynamic analysis and adsorption mechanism are investigated. Importantly, the freestanding and elastic AS was facilitated to assemble into a column-packed device for fixed-bed continuous wastewater treatment, indicative of excellent adsorption efficiency with $1100 \mathrm{mg} \mathrm{g}^{-1}$ just in $50 \mathrm{~min}$. Furthermore, it can be regenerated for more than ten cycles by the simple squeezing method due to its unique compressive property. Considering the priority of low-cost, simple process and eco-friendship, the AS adsorbent derived from biomass resources show a bright future of low cost and renewable material resign of $\mathrm{MB}$ adsorbents, it suggests that the biomass resource could become a promising candidate for industrially applicable and efficient treatments of dye containing effluents.

Supplementary Materials: The following are available online at http://www.mdpi.com/2073-4360/11/6/961/s1, Scheme S1: The involved chemical equations of Scheme 1. Figure S1: The pore size distributions of AS calculated by the mercury intrusion porosimetry method. Figure S2: The XPS survey spectrum of the sample of AS. Figure S3: The images of MB solution before and after batch adsorption. Figure S4: FT-IR spectra of sodium alginate, AS and MB adsorbed onto AS. Figure S5: The TGA analysis result of the sample of AS. Table S1: The MB adsorption capacity of alginate-based adsorbents in literatures. Table S2: The MB adsorption capacity of other reported adsorbents in literatures. 
Author Contributions: X.W. and T.Y. conceived and designed the experiments; X.S. and P.H. performed the experiments; X.S. and F.L. guided the experiments; T.Y., X.W. and R.S. analyzed the data; X.S. wrote the paper; X.W. proposed amendments and addenda to the first draft of the document. All these authors had contributed substantially to this work reported.

Funding: This research was funded by the National Natural Science Foundation of China [51603012] and the Fundamental Research Funds for the Central Universities [2018ZY07].

Conflicts of Interest: No conflict of interest exits in the submission of this manuscript, and the manuscript is approved by all authors for publication. The founding sponsors had no role in the design of the study; in the collection, analyses, or interpretation of data; in the writing of the manuscript, and in the decision to publish the results.

\section{References}

1. Adegoke, K.A.; Bello, O.S. Dye sequestration using agricultural wastes as adsorbents. Water Resour. Ind. 2015, 12, 8-24. [CrossRef]

2. Ahmed, S.M.; El-Dib, F.I.; El-Gendy, N.S.; Sayed, W.M.; El-Khodary, M. A kinetic study for the removal of anionic sulphonated dye from aqueous solution using nano-polyaniline and Baker's yeast. Arab. J. Chem. 2016, 9, S1721-S1728. [CrossRef]

3. Aljeboree, A.M.; Alshirifi, A.N.; Alkaim, A.F. Kinetics and equilibrium study for the adsorption of textile dyes on coconut shell activated carbon. Arab. J. Chem. 2017, 10, S3381-S3393. [CrossRef]

4. Aboelmagd, A.; El-Safty, S.A.; Shenashen, M.A.; Elshehy, E.A.; Khairy, M.; Sakaic, M.; Yamaguchi, H. Nanomembrane canister architectures for the visualization and filtration of oxyanion toxins with one-step processing. Chem. Asian J. 2015, 10, 2467-2478. [CrossRef] [PubMed]

5. Shenashen, M.A.; El-Safty, S.A.; Elshehy, E.A. Monolithic scaffolds for highly selective ion sensing/removal of $\mathrm{Co}(\mathrm{II}), \mathrm{Cu}(\mathrm{II})$, and Cd(II) ions in water. Analyst 2014, 139, 6393-6405. [CrossRef] [PubMed]

6. Gomaa, H.; Shenashen, M.A.; Yamaguchi, H.; Alamoudi, A.S.; El-Safty, S.A. Extraction and recovery of $\mathrm{Co}^{2+}$ ions from spent lithium-ion batteries using hierarchical mesosponge $\gamma-\mathrm{Al}_{2} \mathrm{O}_{3}$ monolith extractors. Green Chem. 2018, 20, 1841-1857. [CrossRef]

7. El-Sewify, I.M.; Shenashen, M.A.; Shahat, A.; Yamaguchi, H.; Selim, M.M.; Khalil, M.M.H.; El-Safty, S.A. Ratiometric fluorescent chemosensor for $\mathrm{Zn}^{2+}$ ions in environmental samples using supermicroporous organic-inorganic structures as potential platforms. Chem. Sel. 2017, 2, 11083-11090. [CrossRef]

8. Derbalah, A.; El-Safty, S.A.; Shenashen, M.A.; Abdel Ghany, N.A. Mesoporous alumina nanoparticles as host tunnel-like pores for removal and recovery of insecticides from environmental samples. ChemPlusChem 2015, 80, 1119-1126. [CrossRef]

9. El Qada, E.N.; Allen, S.J.; Walker, G.M. Adsorption of basic dyes from aqueous solution onto activated carbons. Chem. Eng. J. 2008, 135, 174-184. [CrossRef]

10. Han, R.; Ding, D.; Xu, Y.; Zou, W.; Wang, Y.; Li, Y.; Zou, L. Use of rice husk for the adsorption of congo red from aqueous solution in column mode. Bioresour. Technol. 2008, 99, 2938-2946. [CrossRef]

11. Pearce, C.I.; Lloyd, J.R.; Guthrie, J.T. The removal of colour from textile wastewater using whole bacterial cells: A review. Dyes Pigments 2003, 58, 179-196. [CrossRef]

12. Gómez, J.M.; Galán, J.; Rodríguez, A.; Walker, G.M. Dye adsorption onto mesoporous materials: PH influence, kinetics and equilibrium in buffered and saline media. J. Environ. Manag. 2014, 146, 355-361. [CrossRef] [PubMed]

13. Wan, X.; Zhan, Y.; Long, Z.; Zeng, G.; He, Y. Core@double-shell structured magnetic halloysite nanotube nano-hybrid as efficient recyclable adsorbent for methylene blue removal. Chem. Eng. J. 2017, 330, 491-504. [CrossRef]

14. He, X.; Male, K.B.; Nesterenko, P.N.; Brabazon, D.; Paull, B.; Luong, J.H.T. Adsorption and desorption of methylene blue on porous carbon monoliths and nanocrystalline cellulose. ACS Appl. Mater. Interfaces 2013, 5, 8796-8804. [CrossRef]

15. Lau, Y.-Y.; Wong, Y.-S.; Teng, T.-T.; Morad, N.; Rafatullah, M.; Ong, S.-A. Coagulation-flocculation of azo dye Acid Orange 7 with green refined laterite soil. Chem. Eng. J. 2014, 246, 383-390. [CrossRef]

16. Kokabian, B.; Bonakdarpour, B.; Fazel, S. The effect of salt on the performance and characteristics of a combined anaerobic-aerobic biological process for the treatment of synthetic wastewaters containing Reactive Black 5. Chem. Eng. J. 2013, 221, 363-372. [CrossRef] 
17. Sakkas, V.A.; Islam, M.A.; Stalikas, C.; Albanis, T.A. Photocatalytic degradation using design of experiments: A review and example of the Congo red degradation. J. Hazard. Mater. 2010, 175, 33-44. [CrossRef]

18. Qiu, W.-Z.; Yang, H.-C.; Wan, L.-S.; Xu, Z.-K. Co-deposition of catechol/polyethyleneimine on porous membranes for efficient decolorization of dye water. J. Mater. Chem. A 2015, 3, 14438-14444. [CrossRef]

19. Martínez-Huitle, C.A.; Brillas, E. Decontamination of wastewaters containing synthetic organic dyes by electrochemical methods: A general review. Appl. Catal. B 2009, 87, 105-145. [CrossRef]

20. Fernandez, M.E.; Nunell, G.V.; Bonelli, P.R.; Cukierman, A.L. Activated carbon developed from orange peels: Batch and dynamic competitive adsorption of basic dyes. Ind. Crops Prod. 2014, 62, 437-445. [CrossRef]

21. Sun, L.; Chen, D.; Wan, S.; Yu, Z. Performance, kinetics, and equilibrium of methylene blue adsorption on biochar derived from eucalyptus saw dust modified with citric, tartaric, and acetic acids. Bioresour. Technol. 2015, 198, 300-308. [CrossRef] [PubMed]

22. Li, G.; Zhu, W.; Zhang, C.; Zhang, S.; Liu, L.; Zhu, L.; Zhao, W. Effect of a magnetic field on the adsorptive removal of methylene blue onto wheat straw biochar. Bioresour. Technol. 2016, 206, 16-22. [CrossRef] [PubMed]

23. Chen, C.; Li, F.; Zhang, Y.; Wang, B.; Fan, Y.; Wang, X.; Sun, R. Compressive, ultralight and fire-resistant lignin-modified graphene aerogels as recyclable absorbents for oil and organic solvents. Chem. Eng. J. 2018, 350, 173-180. [CrossRef]

24. Li, F.; Wang, X.; Yuan, T.; Sun, R. A lignosulfonate-modified graphene hydrogel with ultrahigh adsorption capacity for $\mathrm{Pb}(\mathrm{II})$ removal. J. Mater. Chem. A 2016, 4, 11888-11896. [CrossRef]

25. Albadarin, A.B.; Collins, M.N.; Naushad, M.; Shirazian, S.; Walker, G.; Mangwandi, C. Activated lignin-chitosan extruded blends for efficient adsorption of methylene blue. Chem. Eng. J. 2017, 307, 264-272. [CrossRef]

26. Fan, J.; Li, D.; Teng, W.; Yang, J.; Liu, Y.; Liu, L.; Elzatahry, A.A.; Alghamdi, A.; Deng, Y.; Li, G.; et al. Ordered mesoporous silica/polyvinylidene fluoride composite membranes for effective removal of water contaminants. J. Mater. Chem. A 2016, 4, 3850-3857. [CrossRef]

27. Ge, H.; Wang, C.; Liu, S.; Huang, Z. Synthesis of citric acid functionalized magnetic graphene oxide coated corn straw for methylene blue adsorption. Bioresour. Technol. 2016, 221, 419-429. [CrossRef] [PubMed]

28. Shu, Z.; Chen, Y.; Zhou, J.; Li, T.; Yu, D.; Wang, Y. Nanoporous-walled silica and alumina nanotubes derived from halloysite: Controllable preparation and their dye adsorption applications. Appl. Clay Sci. 2015, 112-113, 17-24. [CrossRef]

29. Han, R.; Zhang, J.; Han, P.; Wang, Y.; Zhao, Z.; Tang, M. Study of equilibrium, kinetic and thermodynamic parameters about methylene blue adsorption onto natural zeolite. Chem. Eng. J. 2009, 145, 496-504. [CrossRef]

30. Wang, L.; Cheng, C.; Tapas, S.; Lei, J.; Matsuoka, M.; Zhang, J.; Zhang, F. Carbon dots modified mesoporous organosilica as an adsorbent for the removal of 2,4-dichlorophenol and heavy metal ions. J. Mater. Chem. A 2015, 3, 13357-13364. [CrossRef]

31. Zhang, X.; Li, Z.; Liu, K.; Jiang, L. Bioinspired multifunctional foam with self-cleaning and oil/water separation. Adv. Funct. Mater. 2013, 23, 2881-2886. [CrossRef]

32. Bi, H.; Yin, Z.; Cao, X.; Xie, X.; Tan, C.; Huang, X.; Chen, B.; Chen, F.; Yang, Q.; Bu, X.; et al. Carbon fiber aerogel made from raw cotton: a novel, efficient and recyclable sorbent for oils and organic solvents. Adv. Mater. 2013, 25, 5916-5921. [CrossRef] [PubMed]

33. Gui, X.; Zeng, Z.; Lin, Z.; Gan, Q.; Xiang, R.; Zhu, Y.; Cao, A.; Tang, Z. Magnetic and highly recyclable macroporous carbon nanotubes for spilled oil sorption and separation. ACS Appl. Mater. Interfaces 2013, 5, 5845-5850. [CrossRef] [PubMed]

34. Gui, X.; Wei, J.; Wang, K.; Cao, A.; Zhu, H.; Jia, Y.; Shu, Q.; Wu, D. Carbon nanotube sponges. Adv. Mater. 2010, 22, 617-621. [CrossRef] [PubMed]

35. Radetic, M.; Ilic, V.; Radojevic, D.; Miladinovic, R.; Jocic, D.; Jovancic, P. Efficiency of recycled wool-based nonwoven material for the removal of oils from water. Chemosphere 2008, 70, 525-530. [CrossRef]

36. Sajab, M.S.; Chia, C.H.; Zakaria, S.; Jani, S.M.; Ayob, M.K.; Chee, K.L.; Khiew, P.S.; Chiu, W.S. Citric acid modified kenaf core fibres for removal of methylene blue from aqueous solution. Bioresour. Technol. 2011, 102, 7237-7243. [CrossRef] [PubMed]

37. Deng, H.; Lu, J.; Li, G.; Zhang, G.; Wang, X. Adsorption of methylene blue on adsorbent materials produced from cotton stalk. Chem. Eng. J. 2011, 172, 326-334. [CrossRef] 
38. Dural, M.U.; Cavas, L.; Papageorgiou, S.K.; Katsaros, F.K. Methylene blue adsorption on activated carbon prepared from Posidonia oceanica (L.) dead leaves: Kinetics and equilibrium studies. Chem. Eng. J. 2011, 168,77-85. [CrossRef]

39. Bhatnagar, A.; Sillanpää, M.; Witek-Krowiak, A. Agricultural waste peels as versatile biomass for water purification-A review. Chem. Eng. J. 2015, 270, 244-271. [CrossRef]

40. Yu, J.-X.; Chi, R.-A.; Guo, J.; Zhang, Y.-F.; Xu, Z.-G.; Xiao, C.-Q. Desorption and photodegradation of methylene blue from modified sugarcane bagasse surface by acid $\mathrm{TiO}_{2}$ hydrosol. Appl. Surf. Sci. 2012, 258, 4085-4090. [CrossRef]

41. Adam, F.; Appaturi, J.N.; Khanam, Z.; Thankappan, R.; Nawi, M.A.M. Utilization of tin and titanium incorporated rice husk silica nanocomposite as photocatalyst and adsorbent for the removal of methylene blue in aqueous medium. Appl. Surf. Sci. 2013, 264, 718-726. [CrossRef]

42. Auta, M.; Hameed, B.H. Chitosan-clay composite as highly effective and low-cost adsorbent for batch and fixed-bed adsorption of methylene blue. Chem. Eng. J. 2014, 237, 352-361. [CrossRef]

43. Yan, L.; Chang, P.R.; Zheng, P.; Ma, X. Characterization of magnetic guar gum-grafted carbon nanotubes and the adsorption of the dyes. Carbohydr. Polym. 2012, 87, 1919-1924. [CrossRef]

44. Hassan, A.F.; Abdel-Mohsen, A.M.; Fouda, M.M.G. Comparative study of calcium alginate, activated carbon, and their composite beads on methylene blue adsorption. Carbohydr. Polym. 2014, 102, 192-198. [CrossRef]

45. Wang, Y.; Wang, W.; Wang, A. Efficient adsorption of methylene blue on an alginate-based nanocomposite hydrogel enhanced by organo-illite/smectite clay. Chem. Eng. J. 2013, 228, 132-139. [CrossRef]

46. Ma, T.; Chang, P.R.; Zheng, P.; Zhao, F.; Ma, X. Fabrication of ultra-light graphene-based gels and their adsorption of methylene blue. Chem. Eng. J. 2014, 240, 595-600. [CrossRef]

47. Liu, L.; Wan, Y.; Xie, Y.; Zhai, R.; Zhang, B.; Liu, J. The removal of dye from aqueous solution using alginate-halloysite nanotube beads. Chem. Eng. J. 2012, 187, 210-216. [CrossRef]

48. Draget, K.I.; Taylor, C. Chemical, physical and biological properties of alginates and their biomedical implications. Food Hydrocoll. 2011, 25, 251-256. [CrossRef]

49. Fuks, L.; Filipiuk, D.; Majdan, M. Transition metal complexes with alginate biosorbent. J. Mol. Struct. 2006, 792-793, 104-109. [CrossRef]

50. Robitzer, M.; David, L.; Rochas, C.; Di Renzo, F.; Quignard, F. Nanostructure of calcium alginate aerogels obtained from multistep solvent exchange route. Langmuir 2008, 24, 12547-12552. [CrossRef]

51. Grant, G.T.; Morris, E.R.; Rees, D.A.; Smith, P.J.C.; Thom, D. Biological interactions between polysaccharides and divalent cations: The egg-box model. FEBS Lett. 1973, 32, 195-198. [CrossRef]

52. Obeid, L.; El Kolli, N.; Dali, N.; Talbot, D.; Abramson, S.; Welschbillig, M.; Cabuil, V.; Bée, A. Adsorption of a cationic surfactant by a magsorbent based on magnetic alginate beads. J. Colloid Interfaces Sci. 2014, 432, 182-189. [CrossRef] [PubMed]

53. Peretz, S.; Cinteza, O. Removal of some nitrophenol contaminants using alginate gel beads. Colloids Surf. A 2008, 319, 165-172. [CrossRef]

54. Deze, E.G.; Papageorgiou, S.K.; Favvas, E.P.; Katsaros, F.K. Porous alginate aerogel beads for effective and rapid heavy metal sorption from aqueous solutions: Effect of porosity in $\mathrm{Cu}^{2+}$ and $\mathrm{Cd}^{2+}$ ion sorption. Chem. Eng. J. 2012, 209, 537-546. [CrossRef]

55. Shi,H.; Li, W.; Zhong, L.; Xu, C. Methylene blue adsorption from aqueous solution by magnetic cellulose/graphene oxide composite: Equilibrium, kinetics, and thermodynamics. Ind. Eng. Chem. Res. 2014, 53, 1108-1118. [CrossRef]

56. Liu, G.; Hu, Z.; Guan, R.; Zhao, Y.; Zhang, H.; Zhang, B. Efficient removal of methylene blue in aqueous solution by freeze-dried calcium alginate beads. Korean J. Chem. Eng. 2016, 33, 3141-3148. [CrossRef]

57. Gupta, V.K.; Nayak, A.; Agarwal, S. Bioadsorbents for remediation of heavy metals: Current status and their future prospects. Environ. Eng. Res. 2015, 20,1-18. [CrossRef]

(C) 2019 by the authors. Licensee MDPI, Basel, Switzerland. This article is an open access article distributed under the terms and conditions of the Creative Commons Attribution (CC BY) license (http://creativecommons.org/licenses/by/4.0/). 